\title{
PENETAPAN ELEMEN KUNCI PENGEMBANGAN AGROINDUSTRI PETERNAKAN DENGAN INTERPRETATIVE STRUCTURAL MODELING (ISM)
}

Arie Dharmaputra Mirah

\section{Fakultas Peternakan Universitas Sam Ratulangi Manado 95115}

\begin{abstract}
ABSTRAK
Sub sektor peternakan walaupun memberikan kontribusi yang cukup besar bagi pertumbuhan ekonomi Sulawesi Utara tetapi sampai saat ini belum termasuk komoditas unggulan dalam pengembangan agroindustri. Permasalahan yang harus dikaji dalam usaha pengembangan peternakan adalah belum adanya penetapan/ penerapan strategi yang tepat untuk mampu memaksimalkan potensipotensi yang ada yang memungkinkan peternakan menjadi industri yang kompetitif.

Penelitian dilakukan dengan tahapan sebagai berikut : - Melakukan penelusuran sumbersumber informasi yang dapat memberi gambaran mengenai batasan, pokok kajian, perkembangan dan permasalahan pada sub sector prternakan, pemahaman kewilayahan, pemahaman manajemen stratejik, untuk kemudian menetapkan formulasi tujuan sebagai arah pelaksanaan penelitian. Melakukan survey pakar untuk mengkaji dan menetapkan elemen/sub elemen yang terkait dengan strategi pengembangan peternakan sektor real agroindustri. - Merancang sistem strukturisasi dengan melakukan kajian/penetapan elemen-elemen kunci pengembangan, dengan Interpretative Structural Modeling (ISM). Berdasarkan hasil kajian pakar ditetapkan sebanyak 4 elemen
\end{abstract}

dan 12 sub elemen yang memiliki interaksi yang kuat dengan pengembangan peternakan di Sulawesi Utara. Elemen tersebut kemudian dianalisis tingkat interaksinya dengan teknik ISM-VAXO. Tahap pertama adalah melakukan kajian hubungan kontekstualnya dalam bentuk Matriks SSIM-VAXO. Metode ini telah mampu mengklasifikasi keseluruahn sub elemen ke dalam empat kuadran berdasarkan nilai Drive Power dan DependenceI dan dalam struktur hirarki berdasarkan Rangking dan Level, yang kemudian menginformasikan sub elemen kunci pengembangan peternakan yaitu : sub elemen Penyediaan sumber daya manusia dengan pengetahuan dan keterampilan beternak yang memadai (7) dan sub elemen Peningkatan program pelatihan keterampilan manajerial (8).

\section{Kata kunci: peternakan, strategi, ISM}

\section{ABSTRACT}

Although the livestock sub-sector contributes significantly to the economic growth of North Sulawesi, but to date not include leading commodity in the agro-industry development. The problems to be studied in livestock development efforts is the absence of the establishment / implementation of appropriate strategies to be able to maximize the potentials 
that exist that allow livestock into a competitive industry. The study was conducted through the following steps: Conducting searches of information sources that can give an idea of the limitations, the principal research, development and problems in the sub-sector prternakan, regional understanding, understanding strategic management, then set formulations for the purpose of research towards implementation. Conducting a survey of experts to examine and define the elements / sub-elements associated with the development strategy of the farm estate sector agro-industry. - Designing systems structuring with a review / determination of the development of key elements, with Interpretative Structural Modeling (ISM). Based on the results of expert assessments set by 4 elements and 12 sub-elements that have a strong interaction with the development of animal husbandry in North Sulawesi. Into elements have analyzed the level of interaction with the ISM-VAXO technique. The first stage is to study contextual relationships in matrix form SSIMVAXO. This method has been able to classify all of elements into four quadrants based on the value Drive Power and DependenceI and in a hierarchical structure based on rank and level, which then informs the development of animal husbandry sub key elements namely: Provision of sub-elements of human resources with knowledge and skills appropriate breeding (7) and sub-elements Improved managerial skills training programs (8).

\section{Keywords: livestock, strategy, ISM}

\section{PENDAHULUAN}

Sub sektor peternakan walaupun memberikan kontribusi yang cukup besar bagi pertumbuhan ekonomi wilayah Sulawesi Utara tetapi sampai saat ini belum termasuk komoditas unggulan dalam pengembangan agroindustri.

Agroindustri merupakan tumpuan harapan dalam menyempurnakan sukses bidang pertanian sebagai industri yang mengolah dan memberi nilai tambah pada produk pertanian secara berkelanjutan. Sentuhan bisnis menjadikan agroindustri salah satu pilar utama perekonomian yang dalam menetapkan strategi pengembangannya, selain aspek teknis juga harus merumuskan strategi pengembangan yang mampu mengoptimalkan potensi sumber daya yang dimiliki oleh suatu wilayah.

Formulasi strategi memerlukan kajian mendalam karena merupakan langkah awal yang sangat menentukan pencapaian goal yang ditetapkan. Penelitian ini bertujuan merancang tahapan formulasi strategi dengan melakukan kajian terhadap interaksi antar elemen/sub elemen pengembangan peternakan sebagai hasil survey pakar, untuk mendapatkan rumusan elemen/sub elemen kuncinya. Permasalahan yang harus dikaji dalam usaha pengembangan 
peternakan adalah belum adanya penetapan/penerapan strategi yang tepat untuk mampu memaksimalkan potensipotensi yang ada yang memungkinkan peternakan menjadi industri yang kompetitif dan mewujudkan revitalisasi pertanian.

Simposium Nasional Agroindustri II (1987) merumuskan agroindustri sebagai suatu kegiatan lintas disiplin yang memanfaatkan sumber daya alam (pertanian) sebagai bahan baku industri. Kontribusi agroindustri (termasuk didalamnya industri berbasis peternakan) menjadi sangat vital bagi pertumbuhan ekonomi negara berkembang. Menurut Brown (1994) lebih setengah dari keseluruhan aktivitas manufaktur di negara berkembang adalah agroindustri. Menjelang akhir abad XX sekitar 37 persen manufaktur di wilayah Asia dan Pasifik adalah pada sektor agroindustri. Agroindustri sudah seharusnya dijadikan tumpuan bagi pelaksanaan resource based strategy yang menurut Martani Huseini (1999) merupakan pendekatan terkini dalam fenomena globalisasi dan strategi bersaing yang dapat digunakan dalam menata ulang strategi pemasaran internasional Indonesia.

Manajemen stratejik didefinisikan sebagai seni dan pengetahuan untuk merumuskan, mengimplementasikan, dan mengevaluasi keputusan lintas fungsional yang membuat organisasi mampu mencapai tujuannya. Manfaat prinsip dari manajemen stratejik adalah membantu organisasi membuat strategi yang lebih baik dengan menggunakan pendekatan yang lebih sistematis, logis, dan rasional pada pilihan strategis. Manajemen stratejik mengajarkan bagaimana memaksimalkan efektivitas organisasi secara keseluruhan, disamping mengajarkan bagaimana memperbaiki efisiensinya (Shrivastava 1994, David 2002, Lea et.al 2006).

Tiga elemen yang menjadi fokus manajemen adalah organisasi, lingkungan dan strategi. Elemen organisasi berkaitan dengan kepentingan pelaku (stakeholder) baik secara individu maupun organisasi dalam pencapaian/ pelaksanaan visi, misi dan tujuan organisasi termasuk industri. Elemen lingkungan berkaitan dengan aspek ekonomi (kekuatan pasar dan kompetisi), sosiokultural, lokasi geografis, pemerintah, dan teknologi. Elemen strategi berkaitan dengan tujuan masa depan (future intention) dan keunggulan bersaing (competitive advantage) dari organisasi (McNamee 1992, Shrivastava 1994, Dirgantoro 2001).

Interpretative Structural Modeling (ISM), adalah suatu teknik yang digunakan dalam permodelan yang mampu mensinkronisasi pendapat para ahli dalam memberikan gambaran yang konkrit 
tentang struktur hirarki sub-elemen dari setiap elemen sistem, dan dalam menemukan sub-elemen kunci serta karakter setiap sub-elemen, sebagai basis pengetahuan yang bermanfaat untuk menyusun perencanaan strategi pengembangan agroindustri yang terpadu dan lintas sektor (Machfud 2001).

Menurut Eriyatno (2003), ISM adalah salah satu alat strukturisasi dalam teknik permodelan deskriptif yang digunakan terutama untuk pengkajian oleh suatu tim tetapi juga dapat dipergunakan oleh seorang peneliti. Model-model struktural dihasilkan guna memotret perihal yang kompleks dari suatu sistem melalui pola yang dirancang dengan menggunakan grafis dan kalimat. Hubungan kontekstual antar sub-elemen teknik ISM dapat dikelompokkan dalam beberapa jenis dan interpretasinya.

\section{METODE PENELITIAN}

Penelitian dilakukan dengan tahapan sebagai berikut :

(1) Melakukan penelusuran sumbersumber informasi yang dapat memberi gambaran mengenai batasan, pokok kajian, perkembangan dan permasalahan pada sub sector prternakan, pemahaman kewilayahan, pemahaman manajemen stratejik, untuk kemudian menetapkan formulasi tujuan sebagai arah pelaksanaan penelitian.

(2) Melakukan survey pakar untuk mengkaji dan menetapkan elemen/sub elemen yang terkait dengan strategi pengembangan peternakan sektor real agroindustri, menentukan jenis agroindustri pilihan yang digunakan sebagai objek kajian sistem pengembangan.

(3) Merancang sistem strukturisasi dengan melakukan kajian/penetapan elemenelemen kunci pengembangan, dengan Interpretative Structural Modeling (ISM)

Tahapan dalam teknik ISM-VAXO adalah:

1. Penyusunan Structural Self-

Interaction Matrix - VAXO

(SSIM-VAXO)

2. Transformasi SSIM-VAXO menjadi Reachability Matrix (RM) bilangan biner

3. Pengujian transitive matriks

4. Klasifikasi sub-elemen berdasarkan Driver Power (DP) dan Dependence (D)

5. Penyusunan hirarki berdasarkan rangking sub-elemen 
Tabel 1 Simbol hubungan dan definisi kontekstual antar elemen ISM-VAXO

Simbol hubungan konteks Definisi hubungan kontekstual antar elemen $\left(e_{i j}\right)$ tual antar elemen $i$ dan $j\left(e_{i j}\right)$

\begin{tabular}{|c|c|}
\hline $\mathrm{V}$ & $\begin{array}{l}\text { Elemen } i \text { menyebabkan hubungan kontekstual dengan } j \\
\text { tapi tidak sebaliknya... }\left(e_{i j}=1 \text { dan } e_{j i}=0\right)\end{array}$ \\
\hline A & $\begin{array}{l}\text { Elemen } j \text { menyebabkan hubungan kontekstual dengan } i \\
\text { tapi tidak sebaliknya } \ldots . .\left(e_{i j}=0 \text { dan } e_{j i}=1\right)\end{array}$ \\
\hline X & $\begin{array}{l}\text { Elemen } i \text { dan } j \text { saling menyebabkan hubungan } \\
\text { kontekstual .............................. }\left(e_{i j}=1 \text { dan } e_{i i}=1\right)\end{array}$ \\
\hline $\mathrm{O}$ & $\begin{array}{l}\text { Elemen } i \text { dan } j \text { dan sebaliknya, tidak menyebabkan } \\
\text { hubungan kontekstual ................ }\left(e_{i j}=0 \text { dan } e_{j i}=0\right)\end{array}$ \\
\hline
\end{tabular}

HASIL DAN PEMBAHASAN

Setelah dilakukan Brainstorming dan wawancara mendalam (In depth intervieu), ditetapkan berbagai elemen dan sub

Tabel 2. Elemen dan Sub Elemen pengembangan peternakan

\section{Elemen}

Sub Elemen

1 Breeding 1 Introduksi dan pengembangan ternak unggul

2 Perbaikan mutu genetis dengan persilangan

3 Penelitian dan pengembangan plasma-nufta hewan lokal

2 Feeding

1 Peningkatan ketersediaan pakan bermutu tinggi (hijauan dan konsentrat)

2 Penyediaan industri pengolahan bahan pakan

3 Pengembangan diversifikasi lahan untuk hijauan

3 Manajemen

1 Penyediaan sumber daya manusia dengan pengetahuan dan keterampilan beternak yang memadai

2 Peningkatan program pelatihan keterampilan manajerial

3 Modernisasi system pemeliharaan (perkandangan)

4 Teknologi Hasil 1 Pengembangan usaha agroindustri untuk peningkatan nilai tambah produk peternakan

2 Penelitian dan pengembangan produk olahan

3 Penguasaan aspek pemasaran secara utuh 
Berdasarkan hasil kajian pakar ditetapkan sebanyak 4 elemen dan 12 sub elemen yang memiliki interaksi yang kuat dengan pengembangan peternakan di Sulawesi Utara. Ke 12 sub elemen tersebut (untuk seterusnya disebut elemen) kemudian dianalisis tingkat interaksinya dengan teknik ISM. Tahap pertama adalah melakukan kajian hubungan kontekstualnya dalam bentuk Matriks SSIM-VAXO sebagaimana pada Gambar 1:

\begin{tabular}{|c|c|c|c|c|c|c|c|c|c|c|c|c|}
\hline Elemen & p12 & p11 & $\mathrm{p} 10$ & p9 & $\mathrm{p} 8$ & $\mathrm{p} 7$ & p6 & $\mathrm{p} 5$ & $\mathrm{p} 4$ & p3 & $\mathrm{p} 2$ & $\mathrm{p} 1$ \\
\hline \multicolumn{13}{|c|}{ Hubungan kontekstual } \\
\hline p1 & A & $\mathrm{V}$ & $\mathrm{O}$ & $\mathrm{V}$ & $\mathrm{X}$ & $\mathrm{X}$ & $\mathrm{A}$ & $\mathrm{O}$ & $\mathrm{O}$ & $\mathrm{X}$ & 0 & \\
\hline $\mathrm{p} 2$ & $\mathrm{O}$ & $\mathrm{O}$ & $\mathrm{V}$ & $\mathrm{V}$ & $\mathrm{O}$ & $\mathrm{A}$ & $\mathrm{O}$ & $\mathrm{O}$ & $\mathrm{A}$ & $\mathrm{X}$ & & \\
\hline p3 & $\mathrm{O}$ & $\mathrm{O}$ & A & $\mathrm{O}$ & $\mathrm{O}$ & $\mathrm{A}$ & $\mathrm{O}$ & $\mathrm{O}$ & $\mathrm{O}$ & & & \\
\hline $\mathrm{p} 4$ & $\mathrm{X}$ & $\mathrm{O}$ & $\mathrm{O}$ & $X$ & $X$ & $\mathrm{X}$ & $\mathrm{X}$ & $\mathrm{X}$ & & & & \\
\hline p5 & $\mathrm{X}$ & $\mathrm{O}$ & A & $\mathrm{O}$ & A & $\mathrm{A}$ & $\mathrm{X}$ & & & & & \\
\hline p6 & $\mathrm{O}$ & $\mathrm{O}$ & $\mathrm{O}$ & $\mathrm{O}$ & $\mathrm{O}$ & $\mathrm{A}$ & & & & & & \\
\hline p7 & $\mathrm{V}$ & $\mathrm{O}$ & $\mathrm{V}$ & $\mathrm{X}$ & $\mathrm{A}$ & & & & & & & \\
\hline p8 & $\mathrm{V}$ & $\mathrm{V}$ & $\mathrm{X}$ & $X$ & & & & & & & & \\
\hline p9 & $\mathrm{O}$ & $\mathrm{O}$ & $\mathrm{V}$ & & & & & & & & & \\
\hline p10 & $\mathrm{X}$ & $\mathrm{X}$ & & & & & & & & & & \\
\hline p11 & $X$ & & & & & & & & & & & \\
\hline p12 & & & & & & & & & & & & \\
\hline
\end{tabular}

Gambar 1. Matriks SSIM-VAXO elemen pengembangan peternakan

Elemen-elemen pengembangan peternakan

1 Introduksi dan pengembangan ternak unggul

2 Perbaikan mutu genetis dengan persilangan

3 Penelitian dan pengembangan plasma-nufta hewan lokal

4 Peningkatan ketersediaan pakan bermutu tinggi (hijauan dan konsentrat)

5 Penyediaan industri pengolahan bahan pakan

6 Pengembangan diversifikasi lahan untuk hijauan

7 Penyediaan sumber daya manusia dengan pengetahuan dan keterampilan beternak yang memadai

8 Peningkatan program pelatihan keterampilan manajerial

9 Modernisasi system pemeliharaan (perkandangan)

10 Pengembangan usaha agroindustri untuk peningkatan nilai tambah produk peternakan

11 Penelitian dan pengembangan produk olahan

12 Penguasaan aspek pemasaran secara utuh 
Tabel 3. Hasil Reachability Matrix final dari elemen pengembangan peternakan

\begin{tabular}{|c|c|c|c|c|c|c|c|c|c|c|c|c|c|c|}
\hline \multirow{2}{*}{$\begin{array}{c}\text { SIMBOL } \\
\text { PROGRAM }\end{array}$} & \multicolumn{12}{|c|}{ KAITAN ANTAR SUB-ELEMEN PENDUKUNG SISTEM PENGEMBANGAN } & \multirow[b]{2}{*}{ DP } & \multirow[b]{2}{*}{$\mathbf{R}$} \\
\hline & p1 & p2 & p3 & p4 & p5 & p6 & p7 & p8 & p9 & p10 & p11 & p12 & & \\
\hline p1 & 1 & 0 & 1 & 0 & 0 & 1 & 1 & $\underline{\mathbf{0}}$ & 1 & 0 & 1 & 0 & 6 & 3 \\
\hline p2 & 0 & 1 & 1 & 0 & 0 & 0 & 0 & 0 & 1 & 1 & 0 & 0 & 4 & 4 \\
\hline p3 & 1 & 1 & 1 & 0 & 0 & 0 & 0 & 0 & 0 & 0 & 0 & 0 & 3 & 5 \\
\hline p4 & 0 & 1 & 0 & 1 & 1 & 1 & 1 & 1 & 1 & 0 & 0 & 0 & 7 & 2 \\
\hline p5 & 0 & 0 & 0 & 1 & 1 & 1 & 0 & 0 & 0 & 0 & 0 & 1 & 4 & 4 \\
\hline p6 & 0 & 0 & 0 & 1 & 1 & 1 & 0 & 0 & 0 & 0 & 0 & 0 & 3 & 5 \\
\hline p7 & 1 & 1 & 1 & 1 & 1 & 1 & 1 & 0 & 1 & 1 & 0 & 1 & 10 & 1 \\
\hline p8 & 1 & $\underline{\mathbf{1}}$ & 0 & $\underline{\mathbf{1}}$ & 1 & 1 & 1 & 1 & 1 & 1 & 1 & 0 & 10 & 1 \\
\hline p9 & 0 & 0 & $\underline{1}$ & 0 & 0 & 0 & $\underline{\mathbf{0}}$ & 1 & 1 & 1 & 0 & 0 & 4 & 4 \\
\hline p10 & 0 & 0 & 1 & 0 & 1 & 0 & 0 & 1 & 0 & 1 & 1 & 1 & 6 & 3 \\
\hline p11 & 0 & 0 & 0 & 0 & 0 & 0 & 0 & 0 & 0 & 1 & 1 & 1 & 4 & 4 \\
\hline p12 & 1 & 0 & 0 & 0 & 1 & 0 & 0 & 0 & $\underline{1}$ & 1 & 1 & 1 & 6 & 3 \\
\hline $\bar{D}$ & 5 & 5 & 6 & 5 & 7 & 5 & 4 & 4 & 6 & 7 & 5 & 5 & & \\
\hline $\mathbf{L}$ & 3 & 3 & 2 & 3 & 1 & 3 & 4 & 4 & 2 & 1 & 3 & 3 & & \\
\hline
\end{tabular}

Tahap kedua adalah melakukan transformasi SSIM -VAXO menjadi Reachability Matrix (RM) bilangan biner, kemudian dilanjutkan ke Tahap ketiga yaitu pengujian transitif terhadap konsistensi pada RM untuk mendapatkan Matrik RM final sebagaimana ditampilkan pada Tabel 3.

Pada Tabel 3, terlihat bahwa Sub elemen 7 yaitu Penyediaan SDM yang memiliki pengetahuan dan keterampilan memadai, dan Sub elemen 8 yaitu Peningkatan program keterampilan manajerial menempati posisi Rangking satu dengan nilai Driver Power (DP) terbesar yang didukung dengan nilai tingkat ketergantungan (Dependence $\quad-\quad D$ ) Terkecil.
Tahap keempat adalah pemetaan hasil RM pada Tabel 3, ke Klasifikasi sub-elemen berdasarkan Driver Power (DP) dan Dependence (D) sebagaimana pada Gambar 2:

Klasifikasi sub-elemen digolongkan dalam empat sektor yaitu:

Sektor 1: Weak driver-weak dependent variables (Autonomous). Hubungan peubah di sektor ini dengan sistem relatif kecil atau tidak ada kaitannya.

Sektor 2: Weak driver-strongly dependent variables (Dependent). Peubah pada sektor ini sangat tergantung dari input dan tindakan yang diberikan terhadap sistem terutama dari peubah linkage. 


\begin{tabular}{|c|c|c|c|c|c|c|c|c|c|c|c|c|c|}
\hline \multicolumn{14}{|c|}{12} \\
\hline 11 & & \multicolumn{3}{|c|}{ Independent } & & & + & & & & \multicolumn{2}{|c|}{ Linkage } & \\
\hline 10 & & & & & \multicolumn{2}{|c|}{$\mathrm{p} 7, \mathrm{p} 8$} & & & & & & & \\
\hline 9 & & & & & & & & & & & & & \\
\hline 8 & & & & & & & & & & & & & \\
\hline 7 & & & & & & $\mathrm{p} 4$ & & & & & & & \\
\hline 6 & & & & & & p1,p12 & & $\mathrm{p} 10$ & & & & & \\
\hline 5 & & & & & & & & & & & & & \\
\hline 4 & & & & & & p2,p11 & $\overline{\mathrm{p} 9}$ & $\mathrm{p5}$ & & & & & \\
\hline 3 & & & & & & p6 & p3 & & & & & & \\
\hline 2 & & $\mathrm{Au}$ & no & ous & & & & & & & Dep & ende & \\
\hline 1 & & & & & & & & & & & & & \\
\hline 0 & & & & & & & & & & & & & \\
\hline & 0 & 1 & 2 & 3 & 4 & 5 & 6 & 7 & 8 & 9 & 10 & 11 & 12 \\
\hline
\end{tabular}

DEPENDENCE

Gambar 2. Diagram klasifikasi sub-elemen pemgembangan peternakan

Sektor 3: Strong driver-strongly dependent variables (Linkage). Hubungan antar peubah pada sektor ini tidak stabil. Setiap tindakan pada peubah tersebut akan berdampak pada peubah lainnya.

Sektor 4: Strong driver-weak dependent variables (Independent). Peubah pada sektor ini disebut peubah bebas yang elemen/sub elemennya dapat dianggap sebagai faktor kunci dari sistem.

Pada tahap akhir adalah penyusunan hirarki sub elemen berdasarkan nilai rangking DP dan level D. Hasil kajian menempatkan keseluruhan sub elemen pengembangan peternakan pada 4 Level sebagaimana terlihat pada Gambar 3.

\section{Level 1 \\ Level 2 \\ Level 3 \\ Level 4}

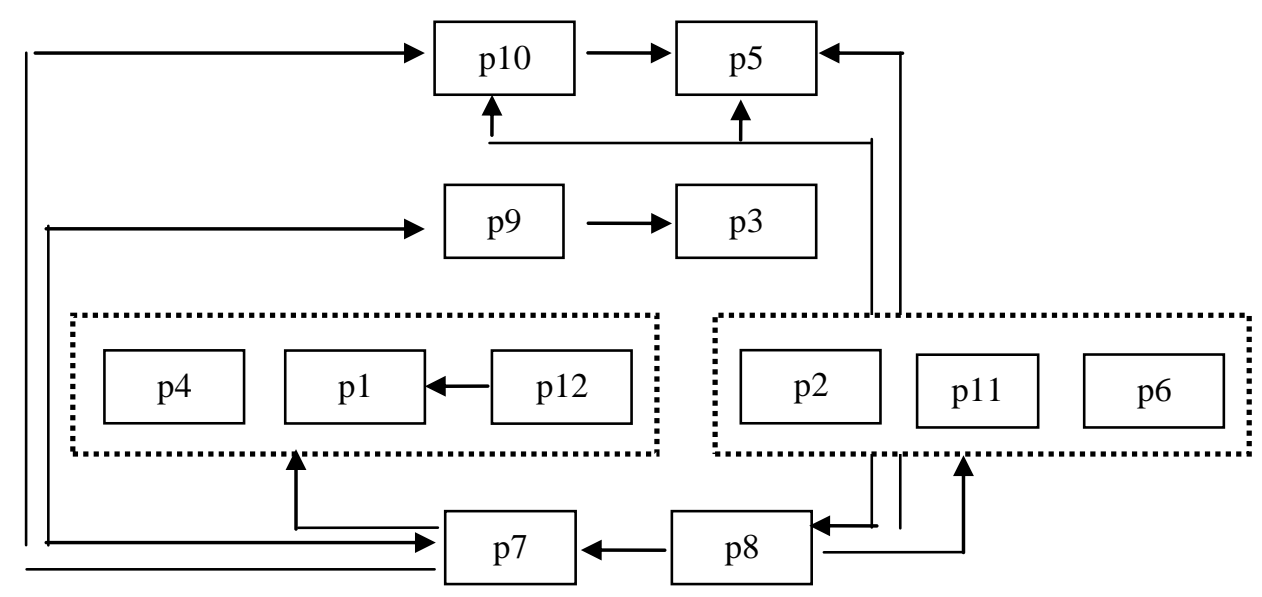

Gambar 3. Struktur hirarki sub-elemen pengembangan peternakan 
Penetapan level hirarki mengindikasikan ketergantungan sub elemen tertentu pada sub elemen pada level di bawahnya

\section{KESIMPULAN}

Hasil kajian pakar telah mengidentifikasi sejumlah 12 sub elemen yang secara kualitatif menentukan pengembangan peternakan di Sulawesi Utara. Prilaku interaksi antar sub elemen telah dianalisis menggunakan metode Interpretatif Structural Modeling (ISM) dengan teknik ISM-VAXO. Metode ini telah mampu mengklasifikasi keseluruahn sub elemen ke dalam empat kuadran berdasarkan nilai Drive Power dan DependenceI dan dalam struktur hirarki berdasarkan Rangking dan Level, yang kemudian menginformasikan sub elemen kunci pengembangan peternakan yaitu : sub elemen Penyediaan sumber daya manusia dengan pengetahuan dan keterampilan beternak yang memadai (7) dan sub elemen Peningkatan program pelatihan keterampilan manajerial (8).

\section{DAFTAR PUSTAKA}

DEPERINDAG, 2000. Kebijakan Nasional Sektor Industri. Jakarta: Departemen Perindus-trian dan Perdagangan.

DPKKT, 2004. Pengembangan ekonomi daerah Berbasis Kawasan Andalan. Info Kajian Bappenas 1: 74-86
Machfud, 2001. Rekayasa model penunjang keputusan kelompok dengan fuzzy-logic untuk system pengembangan agroindustri minyak atsiri [Disertasi]. Bogor: Institut Pertanian Bogor.

Manktelow J. 2004 SWOT Analysis. www.mindtools.com/pages/article/ .visit: April 2006.

Huseini M. 1999. Mencermati Misteri Globalisasi: Menata-ulang strategi pemasaran internasional Indonesia melalui pendekatan Resource Based. Pidato penguku-han Guru Besar Bidang Marketing Internasional Universitas Indonesia. Depok: UI

Manunggal, 2003. Identifikasi Kebutuhan Prasarana dan Sarana Kimpraswil Untuk Mendukung Kawasan Agropolitan Provinsi Sulawesi Utara. Manado: Departemen Kimpraswil.

Saxena, J.P. et.al. 1992. Hierarchy and Classification of Program Plan Element Using Interpretative Structural Modelling. Systems Practice, Vol 12 (6), 651:670.

Element Using Interpretative Structural Modelling. Systems Practice, Vol 12 (6), 651:670. 